\title{
Insights into the Relative DNA Binding Affinity and Preferred Binding Mode of Homologous Compounds Using Isothermal Titration Calorimetry (ITC)
}

\author{
Ruel E. McKnight
}

Additional information is available at the end of the chapter

http://dx.doi.org/10.5772/54061

\section{Introduction}

\subsection{Drug-DNA interactions}

Many biologically significant compounds have been known, for several decades now, to bind non-covalently to nucleic acids.[1-7] Ever since the discovery of the structure of DNA in the 1950s, DNA has been a target for many therapeutic compounds. Several of these compounds have been found to bind to DNA while interfering with the activity of many vital enzymes and protein factors involved in DNA metabolism. Others cleave DNA or cause DNA cross-linking (for example, cisplatin) interfering with cell division and leading to apoptosis. As a result, several DNA-binding compounds have been identified as therapeutic agents in especially the anti-cancer and anti-pathogenic classes. Some of the most notable members of these classes include the Streptomyces derived anthracyclins e.g., daunomycin (daunorubicin) and doxorubicin, have been used for decades, initially as antibiotics, then mainly as antitumor agents.[8] Other known DNA binding agent include mitoxantrone, which has been particularly useful in the treatment of breast cancers, the glycopeptide antibiotic bleomycin which has been used in the treatment of Hodgkin's lymphoma and testicular cancer, amsacrine, bisantrene and various porphyrin derivatives. Even though many of these compounds have exhibited therapeutic potency, there still exist the accompanying unwanted side-effects, due mainly to the lack of selectivity and DNA targeting. Now, even after decades of studies of drug-DNA interactions, the existence of deleterious side-effects remains a huge area of concern and presents the main barrier for progress within the field. So, the question of whether a certain molecule will bind to a specific DNA sequence is currently being probed by several research groups. If we are to 
approach the problem from a fundamental level, such efforts must rely heavily on a fundamental understanding of the predominant contributions to drug-DNA interactions. Although ligand-DNA interactions have been studied, so far there have only been a handful of studies that have probed the factors that govern DNA-binding using homologous series of compounds. This information is especially relevant to the rationale design of novel therapeutics with improved efficacy and specificity. The proposed chapter is designed to yield an understanding of how various features of small molecules govern their binding to DNA and will provide insights into ligand-DNA interactions by studying binding trends within homologous series of compounds. Several studies have suggested that some DNA binding molecules exhibit more than one binding mode while binding in a sequence specific manner. In fact, some researchers have proposed that the therapeutic efficiency of these drugs may be linked to their ability to exhibit mixed binding modes.[9,10] These modes primarily involve intercalation, where planar aromatic molecules slide between adjacent DNA base pairs resulting in significant perturbation of the DNA, and/or minor-groove binding, where molecules with the requisite flexibility and isohelicity with the DNA minor groove are able to fit into the DNA groove, usually with no significant change in the structure of the DNA.

For many years now, microcalorimetry has been utilized to decipher the complete thermodynamic profiles for a number of drug-DNA complexes.[11] Isothermal titration calorimetry (ITC) has been successfully used to parse the thermodynamics of the interactions between drug molecules and DNA.[2,3,11] ITC is regarded as the "gold standard" approach for the determination of binding affinity data in biomolecular interactions. ITC has been used to determine the comprehensive thermodynamic profile of these interactions, by determining enthalpy change $(\Delta \mathrm{H})$ directly (usually in the presence of an excess of the macromolecular binding sites), while determining equilibrium binding constant $(\mathrm{K})$, and number of binding sites (n) by model-fitting routines. Free energy change $(\Delta \mathrm{G})$ and ultimately entropy change $(\Delta \mathrm{S})$ are determined from the known thermodynamic relationships $(\Delta \mathrm{G}=-\mathrm{RT} \operatorname{lnK})$ and $(\Delta \mathrm{G}=\Delta \mathrm{H}-\mathrm{T} \Delta \mathrm{S})$, respectively. Furthermore, heat capacity change $(\Delta \mathrm{Cp})$ may be determined from ITC measurements of $\Delta \mathrm{H}$ over a range of different temperatures $(\Delta \mathrm{Cp}=\mathrm{d} \Delta \mathrm{H} / \mathrm{dT}) \cdot[11]$

In this chapter, we show how isothermal titration calorimetry can be successfully utilized to determine relative DNA binding efficacy, as well as the preferred DNA binding mode for a selection of homologous series of compounds. By comparing the DNA binding characteristics of homologous compounds under identical conditions, we can make robust conclusions as to the most important driving force governing the interaction of ligands to DNA. The chapter will describe two classes of homologous compounds; the naphthalene diimides and chalcogenoxanthyliums. However, the chapter will mainly focus on the naphthalene diimide series. The NDI scaffold has been used by several researchers to design therapeutically significant candidates [12-20] and are used in our studies as model systems to gain additional insight into the binding of "threading" intercalators to DNA. These symmetrical molecules have two substituents on either side of the intercalating moiety, thus necessitating the threading through or involvement of the side chain during binding 
(Figure1).[13,14,17-19] In this geometry, one side chain occupies the minor groove, while the other lies in the major groove. According to some researchers, a threading intercalator has a number of potential advantages since the contact with both DNA grooves provide additional potential sites for recognition and targeting.[12-20] The NDI scaffold has provided a versatile template for the design of many promising derivatives.[12-20]

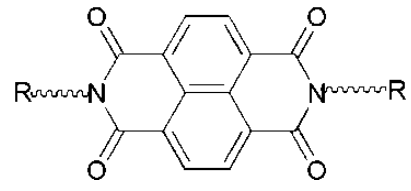

( $\mathrm{R}$ = ethyl- or propyl-amino side chain)

Figure 1. General structure of the naphthalene diimides in this study.

Some NDI derivatives have also been found to selectively bind non-standard structural forms of DNA such as triplexes and G-quadruplexes, which are normally transient and unstable.[21-25] Stabilization of DNA triplexes formed when oligonucleotides (normally referred to as triplex formation oligonucleotide or TFO) bind to DNA duplexes, have been explored in anti-gene therapeutics where expression of deleterious DNA sequences are suppressed by the binding and stabilization of complimentary TFO sequences.[15,21] Formation of transient G-quadruplexes in G-rich sequences have been found to be prominent in telomeres, G-rich ends on chromosomes that protects indispensable genes from being depleted, as well as preventing unwanted chromosomal fusions.[23-25] As a result, some compounds (e.g., certain NDI derivatives) can bind to and stabilize these telomeric G-quadruplexes can block access to these sequences by telomerase enzymes, which are responsible for extending and protecting telomeres and have been found to be over-expressed in $80 \%$ of cancers cells.[24,25] G-quadruplexes have also been found to be prominent in promoter regions, especially in the promoters of oncogenes such as the $c-m y c$ and Ras genes, were, found to be directly linked to the formation of certain cancers.[24,25] Stabilization of these G-quadruplexes in oncogene promoter regions can block access by RNA polymerase, and ultimately blocking expression of these deleterious genes. It is therefore important that we continue to probe ligands systems in order to increase our understanding of the driving force behind ligand-DNA interactions, and to use this knowledge to control their preferred binding mode and sequence.

The NDI compounds were synthesized as previously described.[26] As mentioned above, the NDI scaffold has been used by several groups to design biologically significant compounds.[12-20] In the current series, the quaternary amino group in each side chains is close enough (ethyl- and propyl-amino linker) to the naphthalene core group to allow electrostatic contact with the DNA. Therefore, the cationic quaternary amino groups are close to the DNA when the core ring system intercalates between DNA base pairs. As a result, there is a greater probability for electrostatic interaction with the phosphates in the DNA backbone. The NDI molecules of this study have two substituents on either side of the central naphthalene moiety and differ mainly in substituent size and hydrophobicity. That means, each compound should adopt a threading molecular geometry when bound to DNA via intercalation. Threading NDI compounds analogous to the ones in this study have been 
under investigation for several years as potential therapeutic (especially anticancer) compounds that bind to DNA with improved sequence-selectivity due to their interactions with both DNA grooves.

\subsection{Chalcogenoxanthyliums}

Although stored blood used during surgery and in blood transfusion is generally safe due to improved screening procedures, there is still a chance (a slight risk) that pathogens within the stored blood may be transmitted from donor to recipient.[27,28] This can occur if the blood was collected from an infected individual before there were detectable levels of the causative pathogen. As a result, there remains a need to develop protocols in which to reduce the risk of pathogen transmission, if only in a precautionary or preventative role.

Photodynamic therapy (PDT) is one approach that has been considered as a viable means in which to purge stored blood samples of deleterious pathogens.[27-32] In PDT, light is used along with endogenous oxygen and an appropriate photosensitizer (a molecule that has the ability to absorb light energy, i.e., photoexcitation, and transfer this energy to another chemical entity inducing a change) to treat or reduce an affliction. Photosensitizers are effective mainly because they are able to absorb appropriate light energy and produce excited triplet states at which time they can transfer energy to ground state oxygen (which is also triplet state) via intersystem crossing producing very toxic singlet oxygen species. PDT has been used for years in the treatment of certain cancers and lesions, as well as age-related macular degeneration. Photofrin, a hematoporhyrin belonging to the porphyrin class of compounds, is probably the most well-known and has been used for many years to treat bladder cancers. Other photosensitizers include those in the clorin class (e.g., photochlor), as well as dyes such as phthalocyanine.

PDT can be applied in pathogen reduction, especially in the removal of microbial material from blood products. In this application, PDT is normally referred to as photodynamic antimicrobial chemotherapy (PACT). Compounds containing the xanthylium core (rhodamines and rosamines), are among some of the most highly touted class of compounds being considered for PACT and have been explored by Wagner, Detty and coworkers.[27,31,32] These compounds have been found to selectively accumulate in cancer cells and mitochondria, and have also been considered as p-glycoprotein inhibitors and mitochondrial stains.[33,34] However, the parent rhodamines and rosamines have been mostly ineffective due to short-lived and low yield of triplet excited state upon photoexcitation. Detty and coworkers have synthesized a group of related chalcogenoxanthyliums (Figure 2) that are based on the parent compounds.[33,34]

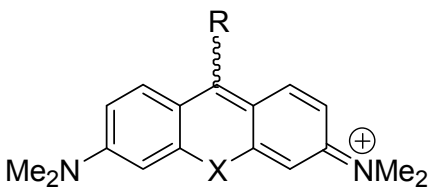

( $X$ = chalchogen, $R=9$-aryl substituent)

Figure 2. General structure for the chalcogenoxanthylium derivatives. 
These chalcogenoxanthylium derivatives represent an improvement over the parent rhodamine and rosamine since the inclusion of the heavier chalcogen (e.g.,S and Se instead of $\mathrm{O})$ provides the known "heavy atom effect" which increases the production of long-lived excited triplet states.[33] Furthermore, the substituents (for example, a 2-thienyl instead of a phenyl) in the 9-position can be "tuned" such that they absorb light at wavelength that avoids hemoglobin attenuation. [33-35]

To date, PACT has been mostly unsuccessful due largely to 1) low efficacy against pathogens, and 2) unwanted background hemolysis of red blood cells.[32] Both these shortcomings are mostly due to the non-specific actions of the photosensitizers when exposed to the requisite light. To circumvent these problems, photosensitizers that are able to target the pathogenic DNA relative to the red blood cells are currently being explored.[32,35] One approach to target these pathogens in the presence of red blood cells is to use photosensitizers that bind strongly to the pathogenic DNA, since mature red blood cells do not contain organelles or genomic nucleic acids.[32,35] The chalcogenoxanthylium derivatives are advantageous to use since their substituents can be tuned such that 1) they absorb light in a spectral region where light attenuation by hemoglobin absorption is avoided, 2) increased yield of singlet excited state that are responsible for destruction of pathogens, and 3) their planarity and hydrophobicity can be altered to monitor the effects on their interaction with DNA. Thus, offering greater opportunity to potentially reduce the incidence of background hemolysis. The DNA binding efficacy and preferred mode of binding of a series of chalcogenoxanthylium dyes were investigated by isothermal titration calorimetry (ITC).[35]

\subsection{Preference for AT-rich vs GC-rich DNA}

In an effort to decipher the preferred DNA binding mode for compounds in this study, a preference for an AT- vs GC-rich sequence will be determined. In order to differentiate preferences for intercalation and/or groove binding, the binding of the compounds of this study to $[p o l y(d A d T)]_{2}$ and $[p o l y(d G d C)]_{2}$ were examined by ITC. Figure 3 shows the structure of [poly(dAdT) $]_{2}$ and [poly $\left.(\mathrm{dGdC})\right]_{2}$ used in this study. It has long been established that known groove binding compounds (e.g., distamycin, berenil, and DAPI) show a strong preference (an order of magnitude or greater) for binding to [poly(dAdT)]2 relative to [poly $(\mathrm{dGdC})]_{2}$.[6] The lower affinity for GC-rich sequences shown by groove binders is largely due to their restricted access to the minor groove of GC sequences caused by the protruding 2$\mathrm{NH}_{2}$ group of guanine. Intercalators are only expected to be affected by this if a substituent is placed into the minor groove during formation of the intercalation complex. It is however expected that compounds that exhibit mixed binding mode (i.e., intercalation and groove binding) will exhibit less $(<10)$ of a preference for the AT sequence.[28,35,36]

5'-ATATATATATATATATATAT-3'

3'-TATATATATATATATATATA-5'
5'-GCGCGCGCGCGCGCGCGCGC-3' 3'-CGCGCGCGCGCGCGCGCGCG-5'

Figure 3. AT-rich and GC-rich DNA sequences used in this study. 
In this chapter, calorimetric data of naphthalene diimide derivatives binding to both calf thymus DNA (ctDNA), as well as AT- and GC-rich DNA sequences will be described. The binding characteristics of selected chalcogenoxanthylium derivatives will also be compared. In an effort to gain insight into the involvement of a minor groove vs. intercalative binding mode, the binding of the compounds to $[p o l y(d A d T)]_{2}$ and $[p o l y(d C d G)]_{2}$ sequences (using ITC) will be discussed. The calorimetric approach will be validated using known/classical DNA intercalating and minor groove binding compounds. Although the main focus of the chapter will be analysis of calorimetric data, the data will also be compared to studies on the same systems using ITC-independents approaches such as a gel electrophoresis based topoisomerase I DNA unwinding assays and fluorescence-based ethidium bromide displacement studies.

\section{Methods and materials}

\subsection{Isothermal titration calorimetry}

In general, calorimetric titrations were carried out on a MicroCal VP-ITC (MicroCal Inc., Northampton, MA), an instrument specifically suited for studying biomolecular interactions. The MicroCal VP-ITC is a highly sensitive microcalorimeter that operates on a power compensation method, whereby heat exchange processes occurring in a sample cell is compared to a reference cell as the instruments keeps the two cell temperatures identical. This results in exothermic processes yielding negative (less than zero) peaks as the instrument decreases the power $(\mu \mathrm{cal} / \mathrm{s})$ supplied to the sample cell relative to the reference cell, while endothermic processes yield positive (greater than zero) peaks as the instrument increases the power supplied to the sample cell compared to the reference cell. The intensity of each peak corresponds to the quantity of the heat exchange. The data was analyzed using the Origin 7.0 software provided by the manufacturer. Experiments were typically run at either $25-30{ }^{\circ} \mathrm{C}$ in MES00 buffer $\left(1 \times 10^{-2} \mathrm{M}\right.$ MES (2( $N$-morpholino) ethanesulfonic acid) containing $1 \times 10^{-3} \mathrm{M}$ EDTA, with the $\mathrm{pH}$ adjusted to 6.25 with $\mathrm{NaOH}$ ) for runs involving calf thymus DNA (ctDNA, ultrapure, Invitrogen). Due to the relative instability of the shorter DNA sequence (particularly the AT-rich sequence), experiments using the $[\text { poly }(\mathrm{dAdT})]_{2}$ and $[\mathrm{poly}(\mathrm{dCdG})]_{2}$ sequences (Midland Certified Reagents, Midland, TX) were done in MES40 (i.e., MES00 with $40 \mathrm{mM} \mathrm{NaCl}$ ). Note, the MES00 buffer was selected for the ctDNA studies due to its low concentration of salt; this would presumably promote stronger binding interactions which would yield more intense peaks and thus better signal/noise ratios. Typically, either 5 or $12 \mu \mathrm{L}$ of the drug solution (typically $5-7 \times 10^{-5} \mathrm{M}$ ) was injected into a buffered solution of DNA (typically $10-15 \times 10^{-6} \mathrm{M}$ in bp, $1.4 \mathrm{~mL}$ ) over 20$24 \mathrm{~s}$ at $240 \mathrm{~s}$ intervals using a $250 \mu \mathrm{L}$ syringe rotating at $300 \mathrm{rpm}$. The initial delay (hold period before injections) was set at $240 \mathrm{~s}$. Before use, samples were degassed at $20^{\circ} \mathrm{C}$ using the ThermoVac accessory (provided by MicroCal Inc.). During the isothermal titration experiments, all injections manifested in a peak that corresponded to the decrease in the power $(\mu \mathrm{cal} / \mathrm{s})$ supplied to keep the temperatures of the sample and reference cells (containing either water or MES buffer) the same for each injection and represented the heat 
given off. Note, in all cases, titration peaks corresponded to negative power compensation resulting from exothermically driven processes. In each case, response signals were corrected for the small heat of dilution associated with the titration of the drug into the MES buffer. The heat of dilution for titrating MES buffer into DNA was found to be negligible. The heat released (i.e., area associated with negative peaks) on binding of the drug to DNA sites was directly proportional to the amount of binding. A binding isotherm of heat released ( $\mathrm{kcal} / \mathrm{mol}$ of injectant) versus the molar ratio ([drug]/[DNA] in bp) was constructed and the data fitted by non-linear least square fitting analysis to an appropriate model.

\subsection{Topoismerase I DNA unwinding assay}

Typically, $0.24 \mu \mathrm{g}$ of supercoiled pUC19 plasmid DNA was incubated with human topoisomerase I (Topo I) enzyme (Invitrogen) for $5 \mathrm{~min}$ at $37^{\circ} \mathrm{C}$. An appropriate amount of the compound of interest was then added (all except for the first two tubes, which serves as controls) and the reaction mixture incubated for a further $1 \mathrm{~h}$ at $37^{\circ} \mathrm{C}$. After incubation, the reaction was terminated using $0.5 \%$ SDS and $0.5 \mathrm{mg} / \mathrm{mL}$ proteinase $\mathrm{K}$. Both the enzyme and compound of interest was then extracted using a mixture of phenol:chloroform:isoamyl alcohol (25:24:1). The remaining DNA sample was then run on an agarose gel (1\%) at $75 \mathrm{~V}$ for $3 \mathrm{~h}$, stained with ethidium bromide for $45 \mathrm{~min}$ and photographed.

\subsection{Ethidium bromide displacement assay}

A solution of ethidium bromide $\left(\mathrm{EtBr}, 5 \times 10^{-6} \mathrm{M}, 1.0 \mathrm{~mL}\right)$ was pre-incubated with ultrapure calf thymus DNA $\left(1 \times 10^{-5} \mathrm{M}\right.$ in base pairs, $\left.1.4 \mathrm{~mL}\right)$ obtained from Invitrogen. at room temperature $\left(22-23^{\circ} \mathrm{C}\right)$ for $15 \mathrm{~min}$ in MES00 buffer, $\mathrm{pH}$ 6.3. Aliquots of exactly $3 \mu \mathrm{L}$ of the compound $\left(7 \times 10^{-5} \mathrm{M}\right)$ were then titrated into the EtBr-DNA solution and the change in fluorescence measured (Photon Technology International fluorometer), after $3 \mathrm{~min}$ incubation periods (excitation $545 \mathrm{~nm}$ and emission $595 \mathrm{~nm}$ ). The addition of $3 \mu \mathrm{L}$ aliquots was continued until the DNA was saturated (i.e., no further change in fluorescence due to EtBr displacement). [28,36] Control experiments showed that the compounds (free or DNAbound) had no significant background fluorescence at the excitation $(545 \mathrm{~nm})$ and emission (595 nm) wavelengths of EtBr.

\section{Results and discussion}

\subsection{Using relative binding affinity for AT- vs GC-DNA to evaluate binding mode}

In order to validate the approach of using relative preferences for AT vs GC to ascertain the preferred DNA binding mode, several known/classical DNA binding compounds were investigated using ITC. These include two compounds known to bind DNA via the minor groove, distamycin A and berenil, (Figure 4) and two compounds known to bind DNA via intercalation (ethidium bromide, normally regarded as the classical DNA intercalator, and daunomycin) (Figure 5).[2,3,6] 
Isothermal titration calorimetric data for distamycin, berenil, daunomycin and ethidium bromide binding to the AT- and GC-rich sequences are shown in Figure 6. As can be seen from the raw data, both minor groove binders distamycin A and berenil show a strong preference for the AT-rich sequence relative to the GC-rich sequence. In fact, ITC signals for each compound binding to the GC-rich sequence was found to be negligible, showing only background signal that was associated with the heats of dilution when the compound was titrated into the cell buffer. Binding constants found for distamycin A and berenil binding to the AT-rich sequence were $2.20 \pm 0.4 \times 10^{7} \mathrm{M}^{-1}$ and $1.76 \pm 0.3 \times 10^{6} \mathrm{M}^{-1}$, respectively.

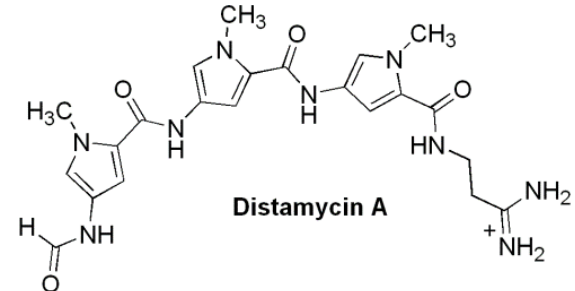<smiles>NC(=[NH2+])c1ccc(N=Nc2ccc(C(N)=[NH2+])cc2)cc1</smiles><smiles>Cn1cc(NC(=O)CNC(N)=[NH2+])cc1C(=O)NCCC(N)=[W]</smiles><smiles>N=C(N)c1ccc(C2=Cc3ccc(C(N)=[NH2+])cc3C2)cc1</smiles>

DAPI

Figure 4. Structures of some common DNA minor groove binding compounds.

A different result was observed with the classical DNA intercalator, ethidium bromide and the known chemotherapeutic DNA intercalator, daunomycin. The isothermal calorimetric data for ethidium bromide and daunomycin showed binding to both the AT- and GC-rich sequences and indicated no significant preference for either sequence. Binding constants obtained for the AT-rich and GC-rich sequence were $1.78 \pm 0.5 \times 10^{5} \mathrm{M}^{-1}$ and $3.38 \pm 0.8 \times 10^{5} \mathrm{M}-$ 1 , and $2.93 \pm 0.63 \times 10^{6} \mathrm{M}^{-1}$ and $3.24 \pm 0.60 \times 10^{5} \mathrm{M}^{-1}$, for ethidium bromide and daunomycin, respectively.

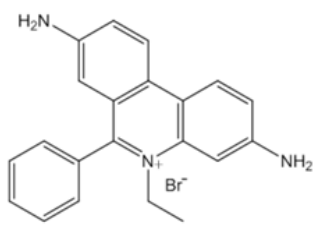

Ethidium bromide

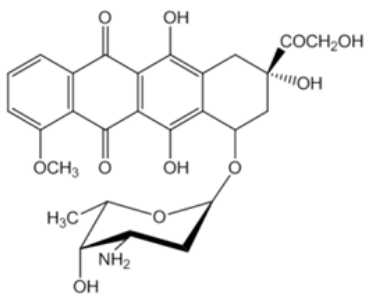

Daunomycin

Figure 5. Structures of two common DNA intercalators.

The results observed for distamycin A, berenil, ethidium bromide and daunomycin are consistent with both distamycin A and berenil binding via the minor groove, since each compound showed a significant preference for the AT-rich sequence, while as expected, 
ethidium bromide and daunomycin bind DNA via intercalation, since neither exhibited a significant preference. This is suggested from the fact that the minor groove in the GC-rich sequence is partially blocked by the protruded 2- $\mathrm{NH}_{2}$ group of guanine, preventing a compound that uses the minor groove for DNA binding to be blocked.[6] This is not the case for the AT-rich sequence. On the other hand, a compound such as ethidium bromide and daunomycin which intercalates into DNA by sliding between adjacent base pairs, will essentially be unimpeded from binding to either the AT or GC-rich sequences. The reported binding modes for distamycin A, berenil, ethidium bromide and daunomycin herein are also consistent with the wealth of literature reports on the binding mode for all four compounds, thus validating our approach.[2,3,6,8,10,37,38]
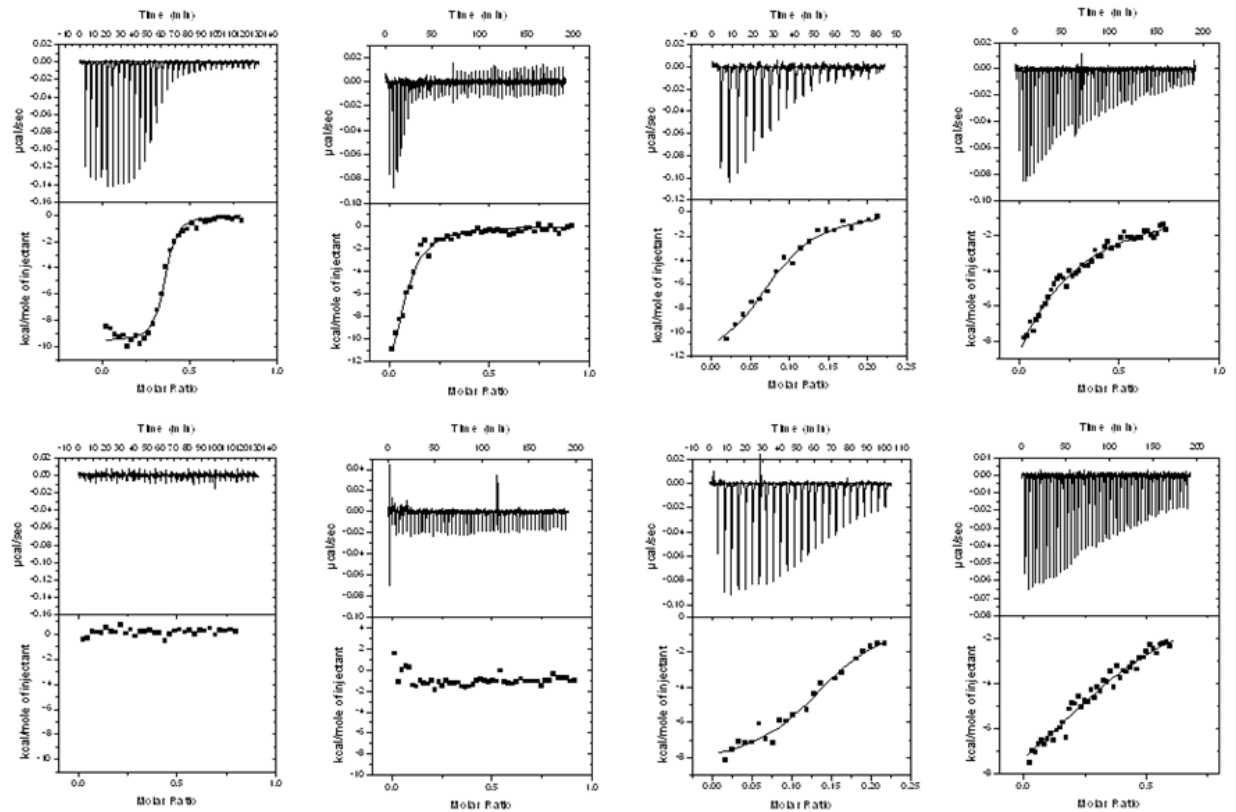

Figure 6. Calorimetric data for the titration of $60 \mu \mathrm{M}$ of the compounds (from left to right): distamycin A, berenil, daunomycin and ethidium bromide into $15 \mu \mathrm{M}$ of AT-rich DNA (top), GC-DNA (bottom) at $30^{\circ} \mathrm{C}$. Binding isotherms (heat change vs drug/DNA molar ratio) were obtained from the integration of raw data and fitted to a "one-site" model

\section{Binding of the NDI derivatives to DNA using ITC}

As was mentioned earlier, the NDI class of compounds is an excellent model system to study DNA binding interactions especially since it offers a useful platform for the syntheses of many homologous series. These molecules are threading intercalators in which side chains on either side of the main intercalating moiety provides the potential for specific recognition sites on the DNA.[12-19] The specific roles of a variety of substituents will be studied with a focus on identifying differential contributions from each moiety. A 
quaternary amino group will also be incorporated into each NDI side chain to provide electrostatic interaction with the negatively charged DNA backbone. The NDI derivatives in this chapter (Figure 7 and 8) were synthesized by Dixon and coworkers and have three main motifs.[26,36]

Ring Size: Compounds that contains a ring ( $N$-methyl pyrrolidine or $N$-methyl piperidine) at the distal end of the side chain, as well as possessing different ring size. To date, the effect of ring size on intercalator-DNA interaction has been mostly unexplored. We have studied two homologous types of NDI that differ by a single carbon with five- vs six-membered heterocyclic rings. These are at identical distances from the main intercalating moiety. The rings are non-aromatic and are not expected to stack with the DNA bases. However, they differ in steric bulk which should have implications during binding. One could predict that NDI-3 will show relatively lower binding affinity than NDI-4, however, the increase in bulkiness might have only kinetic consequences. ${ }^{26}$ We are interested in determining whether these substituent variations might have an effect on both the preferred DNA binding mode adopted by these compounds, and consequently their relative DNA binding affinity. We also compare the effect of having a cyclic structure in the side chain vs. acyclic alkyl substituents.

Linker length: Insights into the effect of changing the linker length for two sets of NDI derivatives (acyclic aliphatic and cyclic aliphatic substituents) will be discussed. In both sets of compounds, the side chain linker length differ by one carbon (ethyl vs propyl). This means the quaternary amino group (present in all the NDI compounds) is one carbon further from the main intercalating core for the propyl linker. For the acyclic aliphatic derivatives, we compare the trimethyl-propylamino (NDI-1p) and dibutylmethylpropylamino (NDI-2p) derivatives (that are one carbon further from the main intercalating core) to the trimethyl-ethylamino (NDI-1e) and dibutylmethyl-ethylamino (NDI-2e) derivatives. For the cyclic aliphatic compounds, the ethyl-linker-containing compound, NDI-3, is compared to the propyl-linker-containing NDI-5. Given the difference in steric bulk of the cyclic aliphatic compared to the acyclic derivatives, there may be steric consequences. We will also be able to gain insights into acyclic vs. cyclic substituent effects on DNA binding.

Substituent length/size: In order to gain additional insights into the role of the side chain size, an analysis of the DNA binding characteristics of NDI compounds that differ in the size and side chain linker-length of their alkyl-amine side chain will also be done. As the length and size of the substituent increases, so does the steric bulk. Of course, hydrophobicity also increases with substituent size. We seek to investigate the effects of steric bulk and hydrophobicity on DNA binding of these derivatives. Hydrophobicity has been reported to be a significant driving force in DNA binding interactions with binding increasing with hydrophobicity.[2,3] We have investigated the relative importance of this factor using a model NDI series in which size/steric contributions should also be a factor. Both hydrophobicity and molecular size increases along the series. If hydrophobicity is the predominant driving force, then one might expect binding to increase with size/hydrophobicity. However, if a size/steric effect dominates, binding should decrease. 

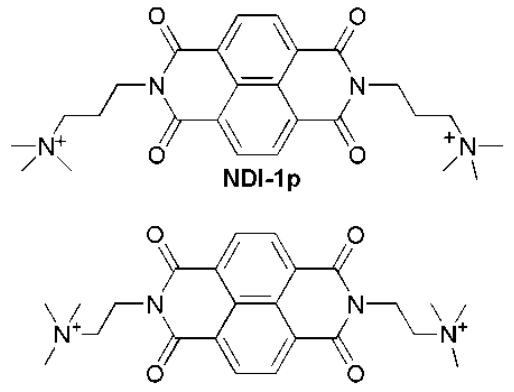

NDI-1e
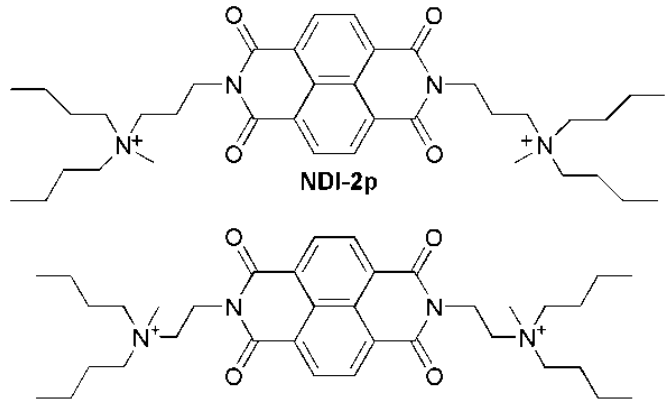

NDI-2e

Figure 7. Representative structure for the acyclic NDI derivatives, showing the ethylamino (ethyl linker) side chain derivatives [NDI-1e (bottom, left) and NDI-2e (bottom, right)] and the propylamino (propyl linker) derivatives [NDI-1p, (top, left) and NDI-2p (top, right)].

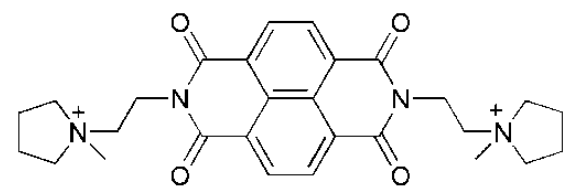

NDI-3

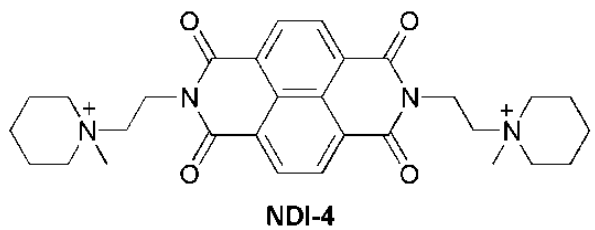

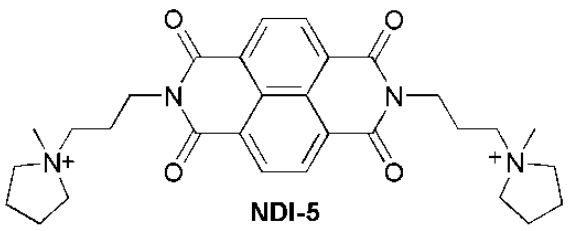

NDI-5

Figure 8. Structures for the cyclic ethylamino NDI derivatives [NDI-3 (top, left) and NDI-4 (bottom, left)] and the cyclic propylamino derivatives NDI-5 (right). Both NDI-3 and NDI-5 contain a side chain Nmethyl pyrrolidine five-membered ring, while NDI-4 contains a six-membered $N$-methyl piperidine ring.

\section{Effect of the side chain ring size and linker length}

In general, the inclusion of a cyclic component in the side chain resulted in a biphasic raw calorimetric data for each cyclic NDI compound binding to DNA (Figure 9). The raw calorimetric data for the cyclic compounds binding to ctDNA were best defined by a model that assumes two types of binding sites $\left(\mathrm{K}_{1}, \mathrm{~K}_{2}\right)$ and argues for the involvement of at least two different types of binding modes for the compounds with ring-containing substituents. This biphasic binding mode has been reported by us for larger members of an acyclic substituent NDI series and will be briefly discussed below.[36] In general, the higher binding constant $\left(\mathrm{K}_{1}\right)$ for the cyclic NDI derivatives was in the order $\left(\sim 10^{7}-10^{8} \mathrm{M}^{-1}\right)$, while a lower binding constant $\left(\mathrm{K}_{2}\right)$ was in the order of $\left(\sim 10^{6} \mathrm{M}^{-1}\right)$ for compounds possessing the $\mathrm{N}$ methyl pyrrolidine ring (NDI-3 and NDI-5) binding to ctDNA. The DNA binding constant for the $N$-methyl piperidine derivative (NDI-4) showed strong but significantly lower binding constants compared to the $N$-methyl pyrrolidine derivatives. Calorimetric data for 
the two compounds that differed only in ring size ( $N$-methyl pyrrolidine vs $N$-methyl piperidine) showed that NDI-3 ( $N$-methyl pyrrolidine substituent) exhibited larger binding constants $\left(\mathrm{K}_{1}=1.17 \pm 0.3 \times 10^{8} \mathrm{M}^{-1}, \mathrm{~K}_{2}=5.6 \pm 0.65 \times 10^{6} \mathrm{M}^{-1}\right)$ as compared to larger NDI-4 $\left(\mathrm{K}_{1}=1.70 \pm 0.4 \times 10^{7} \mathrm{M}^{-1}\right.$ and $\left.\mathrm{K}_{2}=3.26 \pm 0.54 \times 10^{6} \mathrm{M}^{-1}\right)$ when binding to ctDNA. Thus both binding constants were lower for the larger $N$-methyl piperidine derivative. Given that NDI-4 possesses a more bulky $N$-methyl piperidyl substituent suggest that steric hindrance may play a role here. Studies on a series of NDI containing acyclic substituents also found two binding constants; one binding constant was found to be as a result of intercalation, while the other was found to via a non-intercalative mode, presumably via the DNA minor groove.[36] Assuming that the two binding modes found for the cyclic substituents here are similar (given the similarities between the two sets of compounds), the two binding modes found here for the cyclic derivatives are presumed to also be via intercalation (lower binding constant, $\mathrm{K}_{2}$ ) and minor groove binding (higher binding constant, $\mathrm{K}_{1}$ ). In which case, NDI-4 with its larger more bulky substituent may find difficulty in sliding itself through adjacent base pairs. This is of course a requirement for intercalation. Furthermore, given that these compounds possess two substituents on either side of the main intercalating moiety (i.e., threading), one substituent must "thread" through DNA base pairs if it is to adopt an intercalating geometry. Since both binding constant decrease for the $N$-methyl piperidine derivative, the second binding mode (i.e., presumed to be via the minor groove) is also affected sterically.

According to the calorimetrically determined binding constants, the linker length did not appear to have significant role for these cyclic side chain containing derivatives since NDI-5 (ethylamino/ethyl linker) and NDI-3 (propylamino/propyl linker) both had very similar binding constants for both the higher and lower binding sites $\left(\mathrm{K}_{1}=1.08 \times 10^{8} \mathrm{M}^{-1}\right.$, $\mathrm{K}_{2}$ $=5.1 \pm 0.72 \times 10^{6} \mathrm{M}^{-1}$ and $\mathrm{K}_{1}=1.17 \pm 0.3 \times 10^{8} \mathrm{M}^{-1}, \mathrm{~K}_{2}=5.6 \pm 0.65 \times 10^{6} \mathrm{M}^{-1}$, respectively). It therefore appears that the size of the cyclic substituent plays a greater role than the substituent linker in determining the DNA binding affinity.
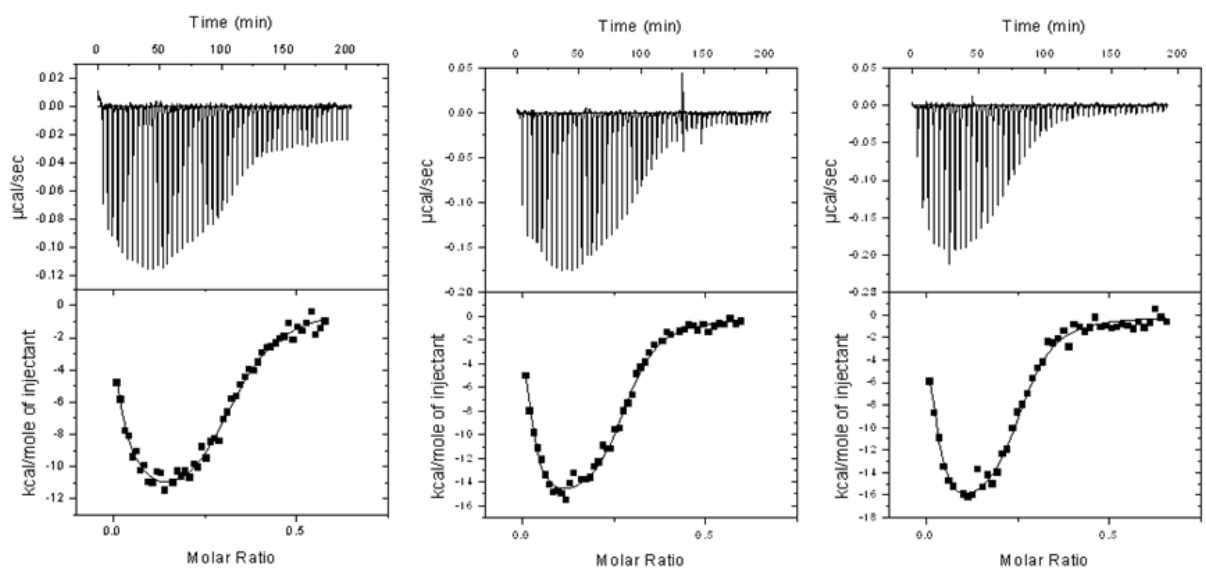

Figure 9. Calorimetric data for the titration of $60 \mu \mathrm{M}$ NDI-4 (left), NDI-3 (middle) and NDI-5 (right) into $12.5 \mu \mathrm{M}$ of ctDNA at $30^{\circ} \mathrm{C}$. Binding isotherms (heat change vs drug/DNA molar ratio) were obtained from the integration of raw data and fitted to a "two-site" model. 


\section{NDI binding mode determination via AT vs GC preference of the cyclic NDI derivatives}

Calorimetric studies were carried out to evaluate preferences for AT vs GC-rich sequences, in an effort to detect a possible minor groove binding mode, implied by the above result (Figure 10). In general, the cyclic NDI derivatives possessing the ethylamino linker (NDI-3 and NDI-4) exhibited a roughly two-fold preference (2.0x for NDI-3, 2.4x for NDI-4) for the AT-rich sequence relative to the GC-rich sequence (Table 1). The difference in affinity for the AT- vs GC-rich sequence is similar to at least one of the acyclic substituent NDI compounds (a dipropylmethyl ethylamino side chain) reported in an earlier study (see section on the acyclic derivatives below), and which was suggested to have a second minor groove binding mode.[36] We therefore suggest here that the cyclic NDI derivatives NDI-3 and NDI-4 does have a minor groove binding mode. It is interesting to note that NDI-4 showed a slightly greater preference for the AT-rich DNA sequence compared to NDI-3, implying a greater involvement of minor groove binding for NDI-4.

The cyclic derivative with the propylamino linker (NDI-5) exhibited even less of a preference ( 1.4x). However, the difference between the NDI-5 binding constant for AT vs GCrich sequences could be considered as the same within experimental error. This result may imply that there is a greater contribution from non-intercalative binding from the cyclic ethylamino derivatives relative to the propylamino derivatives. This result is somewhat similar to what was observed in the series of acyclic substituent NDI derivatives. However, given the small differences in AT vs GC-sequences, this would warrant additional studies to confirm.
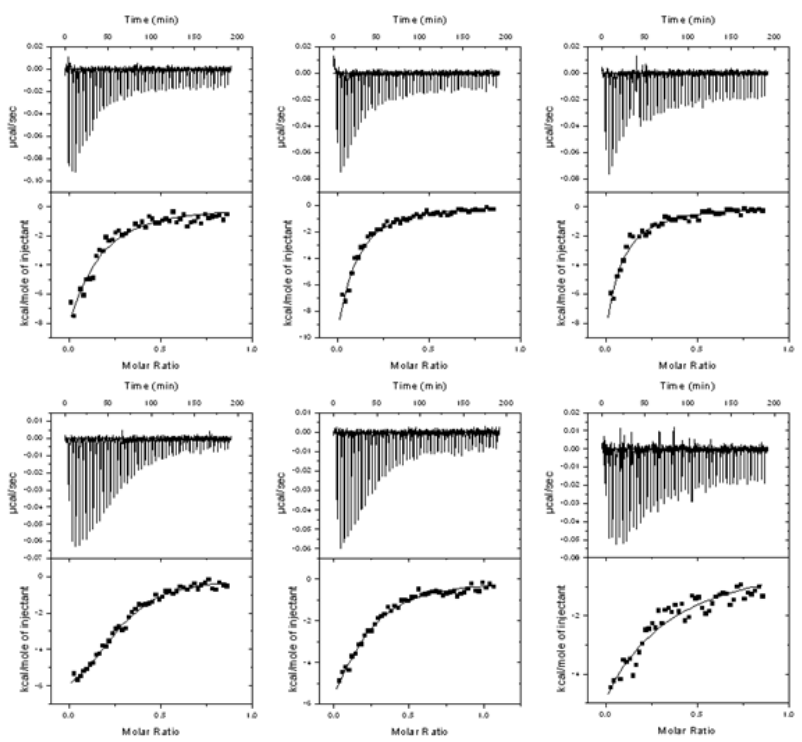

Figure 10. Calorimetric data for the titration of $60 \mu \mathrm{M}$ NDI-5 (left), NDI-3 (middle) and NDI-4 (right) into $15 \mu \mathrm{M}$ of AT-rich DNA (top), GC-DNA (bottom) at $30^{\circ} \mathrm{C}$. Binding isotherms (heat change vs drug/DNA molar ratio) were obtained from the integration of raw data and fitted to a "one-site" model. 


\section{DNA binding mode determination using ITC-independent approaches}

Two additional approaches were also utilized to determine the binding mode involved for the compounds in this study. These were a topoisomerase I DNA unwinding assays (topo assay) and ethidium bromide (EtBr) displacement studies. A brief description of the two techniques is in order. Briefly, the topo assay exploits the ability of topoisomerase I enzyme to relax supercoiled DNA, such as the plasmid pUC19 used in all our studies.[39,40] Under the conditions of our topo assay, supercoiled plasmid pUC19 DNA is first relaxed by using excess topoisomerase I enzyme and then is exposed to the compound under study. After extraction of the compound and enzyme, a compound that was bound via intercalation will cause re-supercoiling of the plasmid DNA. Re-supercoiling is due to the change in DNA linking number that accompanies relaxation by the topoisomerase enzyme and occurs to the extent to which the intercalator molecule was initially bound.[39,40] An intercalating molecule will perturb the DNA such that the DNA will unwind, causing the topoisomerase enzyme (which is present in excess) to relax the DNA, thus changing the linking number. The extent to which DNA unwinding occurs will be dependent upon the extent to which DNA binding occurs, thus the minimum concentration needed to cause complete resupercoiling will be indicative of how much compound was initially bound and thus the relative binding affinity. Conversely, minor groove binders should not induce appreciable re-supercoiling due to negligible DNA unwinding upon binding, and negligible change in DNA linking number.

With the EtBr displacement assays, $\mathrm{EtBr}$, a known intercalator is first bound to DNA, occupying its intercalative sites. The compound of interest is then added to determine whether it is able to displace EtBr from its intercalative sites. Displacement is monitored by a decrease in EtBr-DNA fluorescence.[28,36,41] It is well established that the fluorescence yield of EtBr is enhanced significantly when it binds to DNA. This occurs as EtBr occupies its intercalative sites between bases in the DNA molecule. However, in the presence of another intercalator, there is competition for a limited/defined number of intercalation sites. As the other intercalator molecules are added, they begin to displace EtBr from these intercalative site, increasing the amount of free (unbound) EtBr. This is usually observed as a decrease in EtBr-DNA fluorescence.

Both the topo assay and ETBr displacement assays has been used by our group, as well as other groups, to determine DNA binding mode of DNA binding compounds.[28,35,36,41,42] To validate the topo assay approach, we have run assays on several known DNA binding compounds. These include the classical DNA intercalator, $\mathrm{EtBr}$, and known minor-groove binding compounds such as distamycin A, berenil. Figure $\mathbf{1 1}$ shows representative topo assay for EtBr and berenil.[42] As is expected, the classical DNA intercalator, EtBr, was able to elicit significant re-supercoiling back to the levels of the control (lane 1), whereas, the known minor groove binding compound was unable to do so, even at the high concentrations. In fact, essentially no re-supercoiling was observed for berenil, confirming its known minor groove binding mode. Similarly, we have done validation studies of our EtBr displacement assay, by running studies on DNA binding compounds in which their 
binding modes have already been established (e.g., distamycin A and berenil). As expected, none of the compounds known to be minor groove binders were able to cause appreciable displacement of $\mathrm{EtBr}$ from its intercalative sites, consistent with these compounds binding to non-intercalative sites (Table 1). However, the intercalating molecules were able to displace ethidium bromide effectively, as was evident by the significant decrease in EtBr-DNA complex fluorescence.

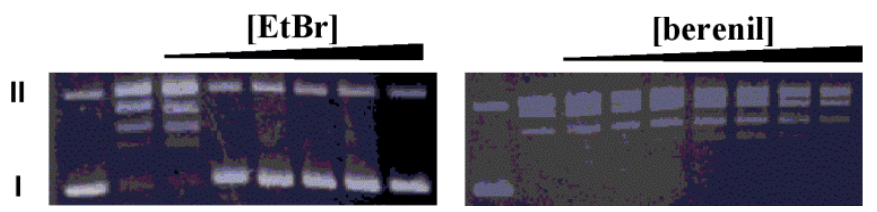

Figure 11. Topo I assay of of the classical DNA intercalator EtBr (left) and the known minor groove binder berenil (right) using 5 units of the topoisomerase enzyme. From left of each gel, lanes 1 contain only DNA (no compound nor topoisomerase) and serve as controls. Lanes 2 contain DNA and topoisomerase, but no compound. Remaining lanes contain DNA, topoisomerase and increasing concentrations of compound (taken from [42]).

\section{Binding mode determination of cyclic NDI derivatives via ITC- independent approaches}

When topo assays were done on the NDI derivatives containing the cyclic amino side chains (NDI-5, NDI-3, and NDI-4), each compound was able to cause re-supercoiling, indicating that intercalation is indeed involved in the binding of each compound to DNA. This was not surprising since NDI compounds are known to bind to DNA via intercalation.[17-19] However, NDI-3 was better able to elicit re-supercoiling than NDI-5, which was in turn better than NDI-4. That is, while NDI-3 was able to cause complete re-supercoiling of our plasmid DNA at $\sim 6 \mu \mathrm{M}, \mathrm{NDI}-4$ requires $>10 \mu \mathrm{M}$ for complete re-supercoiling (Table 1). This suggests that the binding of NDI-3 involves more of an intercalative mode than either NDI5 or NDI-4 and is consistent with what was observed in the ITC studies for these compounds described above. That is, the strength of the lower binding constants $\left(\mathrm{K}_{2}\right)$ was in the order NDI-3>NDI-5>NDI-4. The lower binding constant ( $\mathrm{K}_{2}$ in this report), has been found to be that of the intercalative binding mode for a similar series of NDI.[36] It appears that the bulkier $N$-methyl piperidine is either sterically hindering intercalation, or forcing NDI-4 into a more non-intercalative binding mode, while NDI-5, with its propylamino linker, exhibits lower affinity for the DNA as compared to NDI-4. The lower binding affinity associated with the propylamino linker will be addressed later.

The behavior of the cyclic substituent NDI compounds in the ITC studies and topo assays were also consistent with our EtBr displacement studies which showed that NDI-3 was better able to displace EtBr from its intercalative sites; thus NDI-3 caused a greater decrease in EtBr fluorescence compared to NDI-4 (Table 1). Our EtBr displacement assays also showed that NDI-5 was able to displace EtBr to the same extent as NDI-3, suggesting that both have a similar intercalative strengths. Again, this is consistent with what we observed 
in the ITC and topo assay studies described above. That is, NDI-5 and NDI-3 having very similar $\mathrm{K}_{2}$ (ITC), and both eliciting re-supercoiling of the plasmid DNA at roughly similar concentrations.

\begin{tabular}{|c|c|c|c|c|c|}
\hline Compound & $\begin{array}{c}K_{b}\left(c_{D N A}\right) \\
\left(10^{6} \mathrm{M}^{-1}\right) \\
(\mathrm{ITC})^{\mathrm{a}}\end{array}$ & $\begin{array}{c}K_{b}(\mathrm{AT}) \\
\left(10^{6} \mathrm{M}^{-1}\right) \\
(\mathrm{ITC})^{\mathrm{b}}\end{array}$ & $\begin{array}{c}K_{\mathrm{b}}(\mathrm{GC}) \\
\left(10^{6} \mathrm{M}^{1}\right) \\
(\mathrm{ITC})^{\mathrm{b}}\end{array}$ & $\begin{array}{c}\text { Topo assay } \\
\left(10^{-6} \mathrm{M}\right)^{\mathrm{c}}\end{array}$ & $\begin{array}{c}\text { EtBr } \\
\text { displacement } \\
\text { Assay } \\
(\Delta \mathrm{F} / \mu \mathrm{L})^{\mathrm{d}}\end{array}$ \\
\hline distamycin A & --- & $2.20 \pm 0.4$ & --- & --- & 6 \\
\hline Berenil & --- & $1.76 \pm 0.3$ & --- & --- & 31 \\
\hline $\mathrm{EtBr}$ & --- & $0.18 \pm 0.05$ & $0.34 \pm 0.08$ & 2 & --- \\
\hline daunomycin & --- & $2.9 \pm 0.6$ & $3.24 \pm 0.6$ & --- & --- \\
\hline NDI-1e & $15 \pm 3$ & $1.11 \pm 0.27$ & $1.17 \pm 0.10$ & 3.5 & 400 \\
\hline NDI-2e & $\begin{array}{c}78 \pm 23 \\
3.9 \pm 1.1\end{array}$ & $1.38 \pm 0.15$ & $0.38 \pm 0.09$ & $>6.7$ & 358 \\
\hline NDI-1p & $1.22 \pm 0.16$ & $10.1 \pm 0.7$ & --- & 3 & --- \\
\hline NDI-2p & $0.57 \pm 0.2$ & $8.7 \pm 0.4$ & --- & 5 & --- \\
\hline NDI-3 & $\begin{array}{c}117 \pm 30 \\
5.66 \pm 0.65\end{array}$ & $0.5 \pm 0.09$ & $0.25 \pm 0.05$ & 6 & 949 \\
\hline NDI-4 & $\begin{array}{c}17.0 \pm 4 \\
3.26 \pm 0.54\end{array}$ & $0.39 \pm 0.08$ & $0.16 \pm 0.04$ & $>10$ & 777 \\
\hline NDI-5 & $\begin{array}{c}104 \pm 35 \\
5.10 \pm 0.72\end{array}$ & $1.16 \pm 0.24$ & $0.85 \pm 0.09$ & $>6$ & 1030 \\
\hline
\end{tabular}

${ }^{a}$ MES00 buffer, $\mathrm{pH} 6.25$

${ }^{b}$ MES40 buffer, $\mathrm{pH} 6.25$.

${ }^{c}$ Minimum concentration required for complete re-supercoiling.

${ }^{d}$ Decrease in EtBr fluorescence per $\mu \mathrm{L}$ of compound added.

Data for acyclic NDI-\#e series are from reference [36].

Data for the acyclic NDI-\#p series are from reference [42].

Table 1. Representative DNA binding affinity data for the compounds in this study.

\section{Effect of the length/size of the substituent and linker length (Ethyl vs propyl)}

As was reported by us, data obtained from calorimetric measurements show that the length/size of the substituent plays a significant role in both the preferred binding mode and relative binding affinity of the compounds of these studies.[36] The compounds of this study showed tight binding to DNA with values of $K_{\mathrm{b}}$ between $10^{5}$ to $10^{8} \mathrm{M}^{-1}$, presumably dependent on their preferred mode of binding to DNA. Figure 12 shows the calorimetric data for the four acyclic NDI derivatives (with ethylamino side chain linkers) binding to ctDNA. In that report, we found only a single type of binding constant (binding mode) for the smallest compound in the series (containing a trimethyl-ethylamino side chain).[36] This 

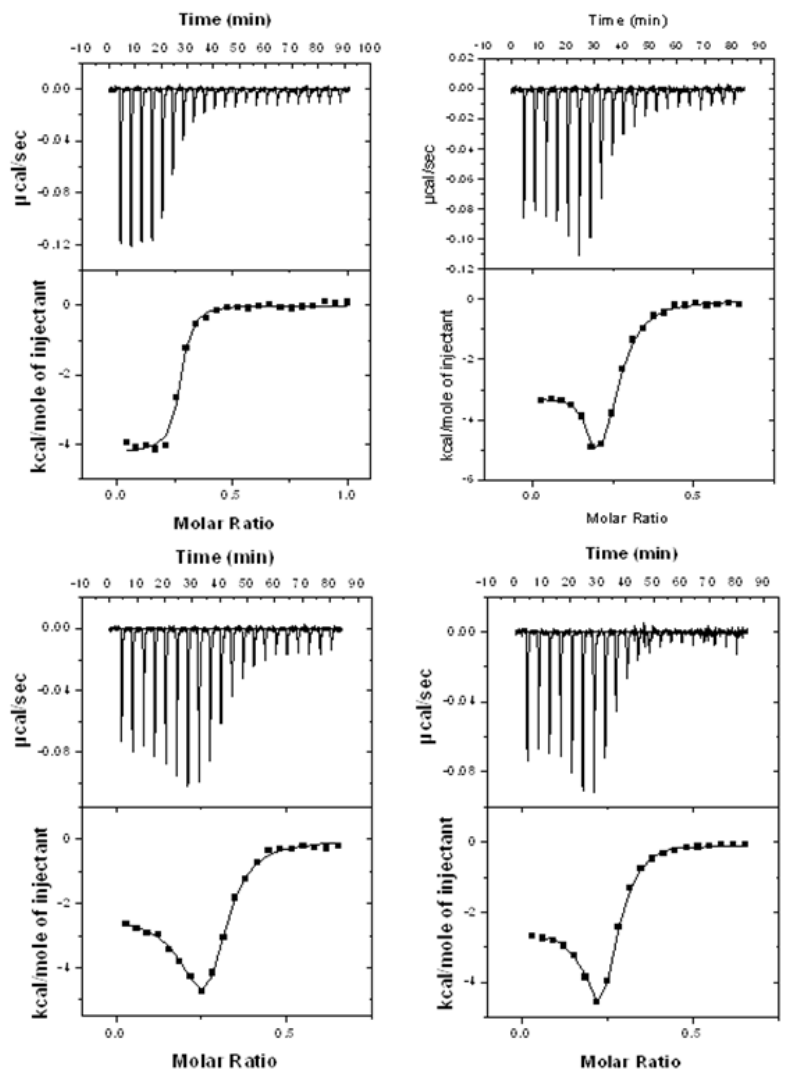

Figure 12. Calorimetric data (raw) for the acyclic ethylamino derivatives binding to ctDNA. In each case, $70 \mu \mathrm{M}$ of the NDI was titrated into ctDNA $(12.5 \mu \mathrm{M})$ at $30^{\circ} \mathrm{C}$. Data is shown for the trimethyl ethylamino derivative NDI-1e (top, left), diethylmethyl ethylamino derivative (top, right), dipropylmethyl ethylamino derivative (bottom, left), and the dibutylmethyl ethylamino derivative NDI-2e (bottom,right). Binding isotherm (heat change vs drug/DNA molar ratio) was obtained from the integration of raw data and fitted to either a "one-site" model (NDI-1e) and a "two-site" model (all others). The plot for NDI-1e and NDI-2e were taken from [36].

was indicated by a single-phased binding isotherm that was well-defined by a one-site binding model. Larger members of the ethylamino series (diethylmethyl-, dipropylmethyland dibutylmethyl-ethylamino substituents) adopted two binding modes; a lower affinity binding mode between 3-4 $\times 10^{6} \mathrm{M}^{-1}$ and an additional higher affinity binding mode of between $31-78 \times 10^{6} \mathrm{M}^{-1}$.[36] This was indicated by a biphasic binding isotherm that was fitted well to a two-site model; one site associated with intercalation and the other associated with minor groove binding. If we compare the results found for the smallest compound in that study, with that of the smallest compound in another study done by us with a similar NDI series with propylamino linker instead,[42] we find that only a single type of binding mode and binding constant (NDI-1e, $K=15 \pm 3 \times 10^{6} \mathrm{M}^{-1}$ and NDI-1p, $\mathrm{K}=1.2$ 
$\pm 0.16 \times 10^{6} \mathrm{M}^{-1}$ ) is found for the smallest member of the series whether the side chain is ethylamino or the one-carbon longer, propylamino substituent.[36,42] However, whereas larger members in the acyclic ethylamino series exhibited a dual binding mode, neither compound in the acyclic propylamino series (referred to as NDI-1p or NDI-2p in this chapter) was found to exhibit more than one binding mode. Additionally, in the ethylamino series, we observe that the relative binding affinity trend for the ethylamino series increased with substituent size. However, this feature was not observed in the propylamino series (one carbon longer on both sides of the main intercalating moiety), since NDI-2p with its dibutylmethyl-propylamino substituent exhibited a lower binding constant $\left(0.57 \pm 0.17 \times 10^{6}\right.$ $\left.\mathrm{M}^{-1}\right)$ compared to smaller homolog (NDI-1p) which had a binding constant of $\left(1.2 \pm 0.16 \times 10^{6}\right.$ $\mathrm{M}^{-1}$ ), a binding mode attributed to intercalative binding.[42] It is also clear that DNA binding affinity was in general greater for the ethylamino derivative, although some of this difference may be attributed to slightly different experimental conditions used in the two studies. It therefore implies that this small structural difference may (1) enable an additional mode of binding, i.e., a linker length that is one carbon shorter resulted in an additional binding mode, as well as (2), enhance the DNA binding mode by greater than an order of magnitude. An explanation for this could be that steric effects may dominate for the propylamino series, resulting in lower DNA binding, especially for the larger members, while hydrophobic and binding mode preferences may be dominant in the ethyl-amino series. The propyl amino derivatives are of course longer especially since the additional carbon linker is on both sides of the molecule, given that these are threading compounds. The longer (more dangling) molecular structure may make it more difficult to thread through adjacent base pairs. However, in the case of the ethylamino series, the solution for the larger substituents appear to be adoption of an additional DNA binding mode. Hydrophobic contributions may also play a role.

\section{Comparison of binding mode for NDI derivative with ethyl vs propyl linker using topo assay}

Comparing the two series with different linker-length (i.e., ethylamino vs propylamino derivatives), it is also interesting to note that generally higher concentrations of the ethylamino derivatives were required for re-supercoiling, despite having higher binding constants as determined by ITC.[36,42] A striking example of this is seen from the fact that more than $6.5 \mathrm{uM}$ of NDI-2e $\left(\mathrm{K}_{1}=78 \pm 23 \times 10^{6} \mathrm{M}^{-1}\right.$ and $\left.\mathrm{K}_{2}=3.9 \pm 1.1 \times 10^{6} \mathrm{M}^{-1}\right)$ was required for supercoiling, while the corresponding propylamino derivative NDI-2p with a significantly lower binding affinity $\left(\mathrm{K}=0.57 \pm 0.17 \times 10^{6} \mathrm{M}^{-1}\right)$ required only $5 \mathrm{uM}$. Again, some of this may also be attributed to different experimental conditions. For example, a greater excess of the topoisomerase enzyme was used in the assays for the ethylamino series. However, this factor alone cannot account for the lack of associated re-supercoiling ability given the disproportionately higher DNA binding constants for the ethylamino derivatives. Overall, a side by side comparison of the topo assay results for the two series (ethylamino vs propylamino) suggests that the ethylamino derivatives displays relative re-supercoiling 
capabilities that are less than expected based on their significantly higher binding affinities. Since the ability to elicit re-supercoiling is primarily based on an intercalative ability, this argues for a greater involvement of non-intercalative binding for ethylamino derivatives relative to their propylamino counterparts.

\section{Binding of the chalcogenoxanthylium derivatives to DNA}

In an effort to further corroborate our DNA binding characterization approach used for the NDI derivatives discussed above using a different/independent homologous series, we will also briefly describe DNA binding studies of a homologous series of chalcogenoxanthylium derivatives to DNA, reported by our group.[35] The chalgenoxanthylium derivatives in this study were synthesized by Detty and coworkers and have been implicated as potential candidates for therapy against blood-borne pathogens.[27,31-33,35].

Using this independent system as a comparison, we have also found that the results obtained from ITC were consistent with that found using topo assay and EtBr displacement studies. These studies have found that the nature of the substituent attached to the main xanthylium core plays a directing role in the preferred binding mode and accompanying DNA binding affinity.[35] While some of the compounds bind to DNA either through intercalation or via the minor groove, some exhibited mixed-binding modes.[35] Excerpts from the DNA binding studies for selected chalcogenoxanthylium derivatives (Figure 13) will now be discussed.

In that report, ITC studies suggested that both the 9-substituent and the identity of the chalcogen play a role in the preferred binding mode and ultimately, the relative DNA binding constant.[35] With a 9-2 thienyl substituent attached to the main xanthylium core (e.g., 2-Se), there appeared to be a preference for intercalation. This was implied from the fact that compounds containing the 9-2 thienyl substituent showed no preference for the ATrich sequence, a feature that would be typical for a minor-groove binder. The 9-2 thienyl also bound to calf thymus DNA with lower affinity as compared to the 9-phenyl derivatives (e.g.,1-Se).[35] DNA intercalators are known to have lower DNA binding affinity as compared to minor-groove binders,[2] so this result may be due to a greater contribution from minor groove binding (i.e., less contribution from intercalation) with the 9-phenyl series. In addition to exhibiting a 2-3 higher binding constant compared to the corresponding 9-2 thienyl derivative, the 9-phenyl series exhibited a slight preference (2-3 times) for binding to [poly(dAdT) $]_{2}$ as compared to the [poly(dGdC)]2. Here again, a possible minor groove binding was implied, since it is known that compounds that bind solely to the DNA minor groove generally show a preference for binding to AT-rich sequences relative to GC-rich sequences due to the occlusion from the GC-rich minor groove by the protruded 2- $\mathrm{NH}_{2}$ group of guanine.[6] As mentioned for the NDI series discussed earlier, it is expected that compounds that bind both via the DNA minor groove and by intercalation (i.e., mixed binding modes) will show a factor of $<10$ preference for AT-rich sequences, depending on the relative contribution from intercalation (i.e., the difference will 
be less as contributions from intercalation increases). The chalcogenoxanthylium derivative bearing a 9-(2-thienyl-5-diethylcarboxamide) substituent (compound 10) exhibited the strongest preference for the $[\text { poly }(\mathrm{dAdT})]_{2}$ sequence. In fact, compound 10 showed essentially no binding to the [poly $(\mathrm{dGdC})]_{2}$ sequence, while binding to [poly(dAdT) $]_{2}$ with a $\mathrm{K}$ of $2.3 \pm 0.4 \times 10^{6} \mathrm{M}^{-1}$.[35]
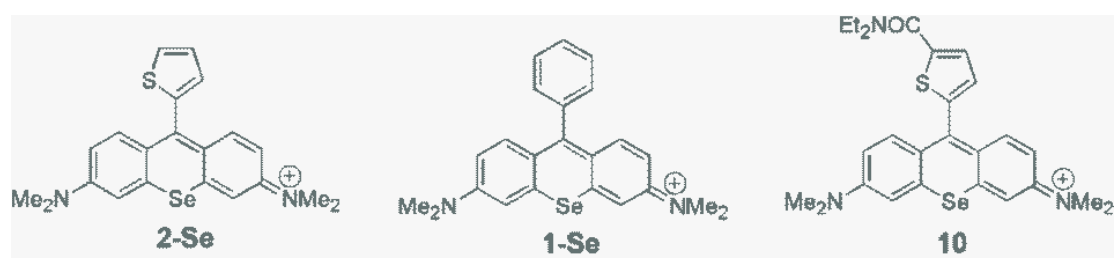

Figure 13. Structures of selected chalcogenoxanthylium derivatives reported in [35]. The 9-2 thienyl derivative (2-Se, left) shown bind mostly via intercalation, while 1-Se derivative (middle) is a mixbinder, and compound $\mathbf{1 0}$ binds primarily via the DNA minor groove.

\section{Binding mode determination of chalcogenoxanylium derivatives via ITC-independent approaches}

As was done for the NDI series discussed earlier, several independent (non-ITC) studies (ethidium bromide displacement and topo assay) were also carried out on the chalcogenoxanthylium derivatives in this study.[35] This was done in an effort to gain additional insights into the preferred DNA binding mode suggested by ITC.

Results from topo assays have been reported by us.[35] These results were in general consistent with the ITC studies on these compounds. We will now report new EtBr data on chalcogenoxanthylium derivatives discussed in this chapter that supports both ITC and topo assay studies.

Further evidence for the preferred DNA binding modes were also observed during ethidium bromide displacement assays on selected members of the chalcogenoxanthylium compounds binding to DNA. These were the seleno derivatives from the 9-2 thienyl series (2-Se), the 9-phenyl series (1-Se), and compound 10 (suggested to have primarily a nonintercalative binding from the ITC studies). While compound 2-Se and 1-Se were both able to cause dislodgement of ethidium bromide from DNA, 2-Se was markedly better able to do so (decrease in fluorescence per $\mu \mathrm{L}$ of compound added was: 2-Se $=711, \mathbf{1}$-Se $=581$, compound $\mathbf{1 0}=350$. Considering that part of the change is fluorescence for the compounds was due to accompanying dilution during the titration, we see here that the order of intercalative ability is $\mathbf{2 - S e}>\mathbf{1}-\mathbf{S e} \mathbf{\mathbf { 1 0 }}$. This order mirrors the results from both ITC and topo assay which showed that 2-Se was a better intercalator than 1-Se, which was in turn better than compound 10. This implies that 2-Se is a stronger intercalator than 1-Se, consistent with both the ITC and topo assay studies. Compound $\mathbf{1 0}$ caused relatively small decreases in ethidium bromide fluorescent (less than any of the NDI derivatives in this study) indicating that it is not a potent displacer of ethidium bromide from its intercalative sites, suggesting 
that compound $\mathbf{1 0}$ is not a strong intercalator, again consistent with the minor groove binding mode implied by both the ITC and topo assay. Given the higher binding constant found for 1-Se relative to 2-Se using ITC, if 1-Se was primarily a DNA intercalator, it would exhibit a greater ability (compared to 2-Se) to dislodge the classical DNA intercalator EtBr from its binding sites. The fact that it did not, strongly supports the idea that the binding of 1-Se to DNA involves other binding modes. Also, the fact compound $\mathbf{1 0}$ showed little ability to dislodge ethidium bromide from DNA, while having the highest binding constant (as determined by ITC studies in an earlier study [35]), supports the idea of compound 10 involving significant non-intercalative DNA binding (presumably, via the minor-groove).

\section{Conclusions}

In this chapter, we have shown how ITC can be successfully used to characterize both the preferred DNA binding mode for series of compounds, as well as their relative DNA binding affinity. For this, we have selected two homologous series of compounds; series of symmetrical NDI threading intercalators in which the side chains are mandatorily involved in DNA binding, and a series of chalcogenoxanthilum derivatives. Both classes of compounds have been shown to have biological activity.

While the homologous NDI derivatives in this study all exhibit DNA intercalative abilities, the substituent on either side of the main intercalating core does play a significant role in determining whether or not additional modes are adopted. This occurs because these compounds require a threading geometry when intercalating between DNA base pairs, i.e., there is a necessity for the side chain to "thread" DNA. The side chains are therefore forced to direct DNA binding. We have found that the cyclic (non-aromatic) substituent at the distal end of a side chain play a significant role in both the DNA binding affinity and the preferred mode of binding. Larger ring sizes face steric barriers and have lower DNA binding affinity. The larger rings may however force additional (non-intercalative) binding modes to be involved. Additional studies may be needed to fully understand the full effects of ring size. Future studies may involve attachment of aromatic rings instead of nonaromatic rings in this study. Having flat aromatic rings on the substituent may enhance site recognition and DNA binding due to the ability to stack. We have also found that even a small modification in the linker length in NDI side chain play a significant role during binding of NDI derivatives of acyclic aliphatic side substituents to DNA. In fact, on comparing side chains with an ethyl linker vs those with a propyl linker, it was found that the ethyl linker could enhance DNA binding by more than an order of magnitude. Possession of the ethyl linker also enabled an additional DNA binding mode of higher affinity. The NDI scaffold therefore represent a versatile template for the design of many promising derivatives with enhanced DNA affinity and have implications in the rationale design of DNA binding compounds with improved site recognition capabilities.

Using an independent system for comparison, the approach of using ITC to study binding to both ctDNA and AT vs GC-rich sequences, was shown to be an efficient and consistent approach in the determination of relative DNA binding affinity and preferred DNA binding 
mode. The ITC studies were well corroborated by ITC-independent studies such as topo assays and EtBr displacement studies, thus exhibiting the efficacy of our approach.

\section{Author details}

Ruel E. McKnight

Department of Chemistry, State University of New York at Geneseo, 1 College Circle, Geneseo, NY, USA

\section{Acknowledgement}

The author is very grateful to Professors Dabney Dixon and Michael Detty for providing the naphthalene diimide and chalcogenoxanthylium compounds, respectively, for this study. I would also like to acknowledge the very diligent students who have contributed to this work over the years (Douglas Jackson, Luke Marr, Kevin Siegenthaler, Eric Reisenauer, Sadia Sahabi, Shivani Polasani, Bilgehan Onogol, Manuel Pintado, Aaron Gleason, and James Keyes).

\section{References}

[1] Bailly C, Colson P, Hénichart J-P, Houssier C (1993) The different binding modes of Hoechst 33258 to DNA studied by electric linear dichroism. Nucleic Acids Res. 21:37053709.

[2] Chaires, JB (1997) Energetics of Drug-DNA Interactions. Biopolymers 44: 201-215.

[3] Haq I (2002) Thermodynamics of Drug-DNA Interactions. Arch. Biochem. Biophys. 403:1-15.

[4] Barcelo, F.; Capo, D.; Portugal, J. (2002) Thermodynamic characterization of the multivalent binding of chartreusin to DNA. Nucleic Acids Res. 30:4567-4573.

[5] Tse WC, Boger DL (2004) A Fluorescent Intercalator Displacement Assay for Establishing DNA Binding Selectivity and Affinity. Acc. Chem. Res. 37:61-69.

[6] Ren J, Chaires JB (1999) Sequence and Structural Selectivity of Nucleic Acid Binding Ligands. Biochemistry 38:16067-16075.

[7] Denny WA (2002) Acridine Derivatives as Chemotherapeutic Agents. Curr. Med. Chem. 9: 1655-1665.

[8] Chaires, JB (1996) Molecular Recognition of DNA by Daunomycin Advances in DNA Sequence Specific Agents. 2:141-167.

[9] Chen AY, Liu LF (1994) DNA Topoisomerases: Essential Enzymes and Lethal Targets. Annu. Rev. Pharmacol. Toxicol. 34, 191-218.

[10] Pilch DS, Kirolos MA, Liu X, Plum GE, Breslauer KJ (1995) Berenil [1,3-bis(4'amidinophenyl)triazene] Binding to DNA Duplexes and to a RNA Duplex: Evidence for Both Intercalative and Minor Groove Binding Properties. Biochemistry 34:9962-9976.

[11] Haq I, Jenkins T, Chowdhry B, Ren J, Chaires JB (2000) Parsing Free Energies of DrugDNA Intercalation. Methods Enzymol. 323: 373-405. 
[12] Hampel SM, Sidibe A, Gunaratnam M, Riou JF, Neidle S (2010) Tetrasubstituted Naphthalene Diimide Ligands with Selectivity for Telomeric G-Quadruplexes and Cancer Cells. Bioorg. Med. Chem. Lett. 20:6459-6463.

[13] Sato S, Hirano A, Takenaka S (2010) Selective Immobilization of Double Stranded DNA on a Gold Surface Through Threading Intercalation of a Naphthalene Diimide having Dithiolane Moieties. Analytica Chimica Acta. 665:91-97.

[14] Lee J, Guelev V, Sorey S, Hoffman DW, Iverson BL (2004) NMR Structural Analysis of a Modular Threading Tetraintercalator Bound to DNA. J Am Chem Soc. 126:14036-14042.

[15] Gianolio DA, Segismundo JM, McLaughlin LW (2000) Tethered Napthalene-based Intercalators for Triplex Stabilization. Nucleic Acids Res. 28: 2128-2134.

[16] Liu ZR, Hecker KH, Rill RL (1996) Selective DNA Binding of (N-alkylamine)Substituted Naphthalene Imides and Diimides to G+C-rich DNA. J Biomol Struct Dyn.14:331-339.

[17] Tanious FA, Yen SF, Wilson WD (1991) Kinetic and Equilibrium Analysis of a Threading Intercalation Mode: DNA Sequence and Ion Effects. Biochemistry 30:18131819.

[18] Wilson, W. D. DNA Intercalators. In DNA and Aspects of Molecular Biology; Kool, E. T., Ed.; Elsevier: New York, 1999; pp 427-476.

[19] Yen S, Gabbay E, Wilson WD (1982) Interaction of Aromatic Imides with Deoxyribonucleic Acid. Spectrophotometric and Viscometric Studies Biochemistry, 21:2070-2076.

[20] Sato S, Kondo H, Takenaka, S, (2006) Linker Chain Effect of Ferrocenylnaphthalene Diimide Derivatives on a Tetraplex DNA Binding. Nucleic Acid Symposium Series 50:107-108.

[21] Rusling D, Peng G, Srinivasan N, Fox K, Brown T, (2009) DNA Triplex Formation with 5-Dimethylaminopropargyl Deoxyuridine. Nucleic Acid Res 87:1288-1296.

[22] Cuenca F, Greciano O, Gunaratnam M, Haider S, Munnur D, Nanjunda R, Wilson W, Neidle S (2008) Tri- and tetra-substituted Naphthalene Diimides as Potent GQuadruplex Ligands. Bioorg. Med. Chem. Lett.18:1668-1673.

[23] Laronze-Cochard M, Kim Y-M, Brassart B, Riou J-F, Laronze J-Y, Sapi J (2009) Synthesis and Biological Evaluation of Novel 4,5-Bis(dialkylaminoalkyl)-Substituted Acridines as Potent Telomeric G-Quadruplex Ligands, Eur. J. of Med. Chem. 44:3880-3888.

[24] Gonzalez, V, Hurley, L (2010) The c-Myc NHE III: Function and Regulation, Annu. Rev. Pharmacol. Toxicol. 50:111-129.

[25] Luedtke, N, (2009) Targeting G-Quadruplexes with Small Molecules. Chimia 63: 134139.

[26] Steullet V, Dixon, DW (1999) Self-Stacking of Naphthalene bis(dicarboximide) Probed by NMR. Perkin Trans. 2:1547-1558.

[27] Wagner, S, Skripchenko, A, Donnelly, D, Ramaswamy, K, Detty, M. (2005), Bioorg. Med. Chem. 13:5927-5935.

[28] McKnight, RE, Ye M, Ohulchanskyy, TY, Sahabi S, Wetzel, BR, Wagner, SJ, Skripchenko A, Detty MR (2007) Synthesis of Analogues of a Flexible Thiopyrylium Photosensitizer 
for Purging Blood-Borne Pathogens and Binding Mode and Affinity Studies of their Complexes with DNA. Bioorg. Med. Chem. 15:4406-4418.

[29] Wainwright M (1998) Photodynamic Antimicrobial Chemotherapy. J. Antimicrob. Chemother 42:13-28.

[30] Dougherty T, Gomer C, Henderson B, Jori G, Kessel D, Korbelik M, Moan J, Pend Q (1998) Photodyanamic Therapy. J. Natl. Caner. Inst. 90:880-905.

[31] Detty MR, Gibson SL, Wagner SJ (2004) Current Clinical and Preclinical Photosensitizers for use in Photodynamic Therapy. J. Med. Chem 47, 3897-3915.

[32] Wagner, SJ, Skripchenko A, Cincotta L, Thompson-Montgomery D, Awatefe H (2005) Use of a Flexible Thiopyrylium Photosensitizer and Competitive Inhibitor for Pathogen Reduction of Viruses and Bacteria with Retention of Red Cell Storage Properties. Transfusion 2005, 45, 752-760.

[33] Calitree B, Donnelly D, Holt J, Gannon M, Nygren C, Sukumaran D, Autschbach J, Detty M. (2007) Tellurium Analogues of Rosamine and Rhodamine Dyes: Synthesis, Structure, ${ }^{125} \mathrm{Te} \mathrm{NMR}$, and Heteratom Contribution to Excitation Energies. Organometallics 26:6248-6257.

[34] Gibson S, Hilf R, Donnelly D, Detty M (2004) Analogues of Tetramethylrosamine as Transport Molecules for and inhibitors of P-Glycoprotein-Mediated Multi-Drug Resistance. Bioorg. Med. Chem. 12:4625-4631.

[35] McKnight, RE, Onogul B, Polasani SR, Gannon MK, Detty MR (2008) Substituent Control of DNA Binding Modes in a Series of Chalcogenoxanthylium Photosensitizers as Determined by Isothermal Titration Calorimetry and Topoisomerase I DNA Unwinding Assay. Bioorg. Med. Chem. 16:10221-10227.

[36] McKnight, RE, Reisenauer, E, Pintado, MV, Polasani, SR and Dixon, DW (2011) Substituent Effect on the Preferred DNA Binding Mode and Affinity of a Homologous Series of Naphthalene Diimides, Bioorg. Med. Chem. Lett. 21:4288-4291.

[37] Barcelo F, Portugal J, (1993) Berenil Recognizes and Changes the Characteristics of Adenine and Thymine Polynucleotide Structures. Biophys. Chem. 47:251-260.

[38] Remata D, Mudd C, Berger R, Breslauer K (1993) Thermodynamic Characterization of Daunomycin-DNA Interactions: Comparison of Complete Binding Profiles for a Series of DNA Host Duplexes. Biochemistry 32:5064-5073.

[39] Pommier, Y, Covey J-M, Kerrigan D, Markovits J, Pham R (2007) DNA Unwinding and Inhibition of Mouse Leukemia L1210 DNA Topoisomerase I DNA Intercalators. Nucleic Acids Res. 15:6713-6731.

[40] Dziegielewski J, Slusarski B, Konitz A, Skladanowski A, Konopa (2002) Intercalation of Imidazoacridinones to DNA and its Relevance to Cytotoxic and Antitumor Activity. J. Biochem. Pharmacol. 63:1653-1662.

[41] Boger DL, Fink BE, Brunette, SR, Tse WC, Hedrick, MP (2001) A Simple, HighResolution Method for Establishing DNA Binding Affinity and Sequence Selectivity. J. Am. Chem. Soc. 123:5878-5891.

[42] McKnight, R. E.; Gleason, A. B.; Keyes, J. A.; Sahabi, S. (2007) Binding Mode and Affinity Studies of DNA Binding Agents Using Topoisomerase I DNA Unwinding Assay. Bioorg. Med. Chem. Lett. 17:1013-1017. 